\title{
Modulation of P-glycoprotein Expression and Function under Disease States in Rats and Humans
}

Teruo Murakami*, Masashi Ishiguro and Keisuke Oda

Laboratory of Biopharmaceutics and Pharmacokinetics, Faculty of Pharmaceutical Sciences, Hiroshima International University, 5-1-1

Hirokoshingai, Kure, Hiroshima 737-0112, Japan

P-glycoprotein (P-gp), an ATP-binding cassette (ABC) efflux transporter, recognizes a variety of structurally and pharmacologically unrelated, various neutral and positively charged lipophilic compounds. P-gp is expressed in the membrane of various normal tissues including the adrenal grands, brain, eye, kidney, liver, muscle, placenta, small and large intestine, skin, and so on, not only in multidrug-resistant cancer cells. P-gp suppresses the influx of various harmful substances including clinically important drugs and facilitates their efflux out of cells, together with other $A B C$ efflux transporters such as multidrug resistance-associated proteins (MRPs) and breast cancer resistance protein (BCRP). For example, in the small intestine, these $\mathrm{ABC}$ transporters suppress the intestinal absorption of their substrate drugs, more or less [1]. Many drugs and supplements can cause the modulation of expression and function of P-gp, P-gp-mediated drug-drug interactions (DDI), as well as the cases for metabolic enzyme CYP3A4. For example, cyclosporine, a $\mathrm{P}$-gp substrate/inhibitor, is reported to cause DDIs with more than 800 P-gp- and CYP3A-related drugs [2]. Natural products such as grapefruit juice, polyphenols, and St. John's wort are also typical modulating agents of P-gp. Turton-Weeks et al. reported that transplant patients using St John's wort concomitantly with cyclosporine or other medications need close monitoring, and transplant coordinators are in a critical position to educate transplant recipients about the potential risks of herbal medication usage [3]. In addition to the modulation of P-gp by such exogenous substances, the disease state itself can also modulate P-gp expression and function greatly and systemically, possibly due to the modulation of physiological parameters including the levels of endogenous substances in the body. The changes of gastrointestinal physiology such as $\mathrm{pH}$, membrane permeability, gastrointestinal transit, and so on in the elderly, in pediatric patients, and in patients with gastrointestinal diseases are reported recently [4]. Previously, we found that P-gp function in the liver, kidney and brain was significantly suppressed under glycerol-induced acute renal failure (ARF) in rats, even though the protein level of P-gp remained unchanged in the liver and brain, and increased in the kidney [5]. As well, P-gp function was systemically suppressed under CCl4-induced acute hepatic failure (AHF), though the protein level of P-gp remained unchanged in the kidney and brain, and increased in the liver in rats [6]. The P-gp function in the intestine of AHF rats also decreased with no significant change of P-gp expression. Accordingly, the results also demonstrated that the actual in vivo P-gp function under disease states cannot be predicted merely from in vitro functional studies nor from P-gp expression levels [7]. Based on these results, we thought that the systemic suppression of P-gp function under disease states such as $\mathrm{ARF}$ and AHF was due to the alteration of plasma concentrations or components of endogenous P-gp-related substances, and the increase in P-gp protein level in the targeted injured tissues (kidney in ARF and liver in AHF) was thought to be an adaptative response to the reduced function. The contribution of endogenous substances in the systemic P-gp suppression under disease states was examined by comparing the inhibitory effects on P-gp function in vitro between normal rat plasma and disease rat plasma [8]. The systemic modulation of P-gp expression and function, together with many other $\mathrm{ABC}$ and solute carrier (SLC) transporters and metabolic enzymes, under disease

\section{Publication History:}

Received: December 06, 2017

Accepted: December 12, 2017

Published: December 14, 2017

\section{Keywords:}

P-glycoprotein, ATP-binding cassette, Gastrointestinal diseases, liver transplantation, Human, Cell transporters, Bioavailabilities

states has also been reported by many research groups as follows: Naud et al. reported the decrease in P-gp expression in the kidney, increase in P-gp expression in the liver, reduction in P-gp activity and expression in the intestine, and reduction in $\mathrm{P}$-gp expression with unchanged P-gp activity in the brain in partially nephrectomized chromic renal failure (CRF) rats [9-13]. Sun et al. reported that renal failure alters not only the renal elimination, but also the non-renal disposition of drugs that are extensively metabolized by the liver [14]. Like this, disease states often affect the expression and function of P-gp systemically at least in animal studies.

Sun et al. also reported that the increase in drug AUCs in subjects with advanced renal disease for drugs that are not renally excreted is consistent with uremic toxin effects on either intestinal or hepatic cell transporters, metabolizing enzymes, or both [14]. Kaplan et al. reported the low oral bioavailabilities of cyclosporine and tacrolimus in a small bowel transplant recipient, in which the allograft ileum showed a high P-gp activity than that obtained from other normal subjects [15]. Buchman et al. reported the significantly higherthan-average requirements of tacrolimus dose, possibly due to the significantly higher P-gp protein level in the duodenum of patient with active Crohn's disease [16]. Fakhoury et al. reported the high levels of duodenal P-gp mRNA in children with Crohn's disease than in the duodenum normal tissue [17]. Englund et al. reported that P-gp expression was strongly reduced in the gut mucosa of individuals with active inflammation compared with controls and was negatively correlated with the levels of IL-6 mRNA [18]. Gutmann et al. reported the reduction of P-gp only in inflamed tissue of patients with active ulcerative colitis with comparable P-gp expression in unaffected mucosa of ulcerative colitis patients [19]. Westerlund et al. reported the reduced mRNA levels of MDR1 (P-gp) in human striatum in Parkinson patients compared with control individuals [20]. Ufer et al.

"Corresponding Author: Prof. Teruo Murakami, Laboratory of Biopharmaceutics and Pharmacokinetics, Faculty of Pharmaceutical Sciences, Hiroshima International University, 5-1-1 Hirokoshingai, Kure, Hiroshima 737-0112, Japan; E-mail: t-muraka@ps.hirokoku-u.ac.jp

Citation: Murakami T, Ishiguro M, Oda K (2017) Modulation of P-glycoprotein Expression and Function under Disease States in Rats and Humans. Int J Clin Pharmacol Pharmacother 2: 130. doi: https://doi.org/10.15344/2017/2456$3501 / 130$

Copyright: (C) 2017 Murakami et al. This is an open-access article distributed under the terms of the Creative Commons Attribution License, which permits unrestricted use, distribution, and reproduction in any medium, provided the original author and source are credited. 
Citation: Murakami T, Ishiguro M, Oda K (2017) Modulation of P-glycoprotein Expression and Function under Disease States in Rats and Humans. Int J Clin Pharmacol Pharmacother 2: 130. doi: https://doi.org/10.15344/2017/2456-3501/130

Page 2 of 3

reported the downregulation of P-gp in the sigmoidal biopsies of ulcerative colitis patients with a possible contribution from IL8 [21]. Blokzijl et al. reported the strong suppression of P-gp mRNA levels in inflamed intestinal epithelium of patients with gastrointestinal disorders such as Crohn's disease, ulcerative colitis, collagenous colitis and diverticulitis [22]. Provenzani et al. reported that kidney transplant recipients carrying the ABCB1 (P-gp) 2677T/A allele required significantly higher daily tacrolimus doses than subjects homozygous for the wild-type allele [23]. Zhang et al. reported that the expression rate of P-gp in patients with ulcerative colitis was significantly lower than that in the control group [24]. Andersen et al. reported that the low P-gp protein levels, high MRP2 gene expression and low BCRP gene expression in intestinal tissue are early events in colorectal carcinogenesis through increasing intracellular exposure to carcinogenic substrates $[25,26]$.

The relationship between the intestinal P-gp levels and required oral doses of immunosuppressants in recipients of living-donor liver transplantation (LDLT) are extensively studied. Hashida et al. reported that the mRNA expression level of P-gp, but not CYP3A4, was inversely related to the concentration/dose ratio of tacrolimus, and high levels of P-gp, but not CYP3A4, were strongly associated with reductions in survival rates after LDLT [27]. Masuda et al. found that the recipient of second LDLT required very large oral doses of cyclosporine, approximately 4.4-fold of the first LDLT, due to the marked increase of intestinal P-gp level after the second LDLT [28]. Masuda et al. also found a good inverse correlation between the tacrolimus concentration/dose ratio and the intestinal mRNA level of MDR1, and reported that intestinal MDR1 mRNA level is a useful molecular marker for determination of the personalized oral dose of tacrolimus in recipients of LDLT immediately after surgery [29]. Sharaki et al. reported that the daily dose requirements of cyclosporine in renal transplant recipients were significantly higher in T allele MDR1 2677G>T GG genotype as compared to GT/TT genotypes at 3, 6, and 9 months post plantation [30].

In conclusion, the expression and function of P-gp can be modulated systemically, more or less, under disease states. The frequency and severity of DDIs could also be increased under disease states. The modulation of in vivo P-gp function will not always be predicted merely from the expression level of P-gp and/or in vitro P-gp function, because of the absence of endogenous P-gp-related substances. The examination of plasma or plasma components obtained from patients in in-vitro P-gp functional studies can suggest the contribution of endogenous substances in the systemic in-vivo modulation of P-gp function. Careful monitoring of pharmacological efficacy and side effects is needed during pharmacotherapy under certain disease states. Accumulation of information regarding the in vivo $\mathrm{P}$-gp function and expression under various disease states is also necessary for further safe and effective pharmacotherapy with P-gp/ CYP3A-related drugs.

\section{Competing Interests}

The authors declare that they have no competing interests.

\section{References}

1. Murakami T, Takano M (2008) Intestinal efflux transporters and drug absorption. Expert Opin Drug Metab Toxicol 4: 923-939.

2. https://www.drugs.com/drug-interactions/cyclosporine.html
3. Turton-Weeks SM, Barone GW, Gurley BJ, Ketel BL, Lightfoot ML, et al. (2001) St John's wort: a hidden risk for transplant patients. Prog Transplant 11:116-120.

4. Bai JPF, Burckart GJ, Mulberg AE. (2016) Literature Review of Gastrointestinal Physiology in the Elderly, in Pediatric Patients, and in Patients with Gastrointestinal Diseases. J Pharm Sci. 105:476-483.

5. Huang ZH, Murakami T, Okochi A, Yumoto R, Nagai J, et al. (2000) Expression and function of P-glycoprotein in rats with glycerol-induced acute renal failure. Eur J Pharmacol 406: 453-460.

6. Huang ZH, Murakami T, Okochi A, Yumoyo R, Nagai J, et al. (2001) Expression and function of P-glycoprotein in rats with carbon tetrachlorideinduced acute hepatic failure. J Pharm Pharmacol 53: 873-881.

7. Yumoto R, Murakami T, Takano M (2003) Differential effect of acute hepatic failure on in vivo and in vitro P-glycoprotein functions in the intestine. Pharm Res 20: 765-771.

8. Murakami T, Yumoto R, Nagai J, Takano M (2002) Factors affecting the expression and function of P-glycoprotein in rats: drug treatments and diseased states. Pharmazie 57:102-107.

9. Dreisbach AW, Lertora JJ (2008) The effect of chronic renal failure on drug metabolism and transport. Expert Opin Drug Metab Toxicol 4: 1065-1074.

10. Naud J, Michaud J, Leblond FA, Lefrancois S, Bonnardeaux A, et al. (2008) Effects of chronic renal failure on liver drug transporters. Drug Metab Dispos 36: 124-128.

11. Naud J, Michaud J, Beauchemin S, Hébert MJ, Roger M, et al. (2011) Effects of chronic renal failure on kidney drug transporters and cytochrome P450 in rats. Drug Metab Dispos 39: 1363-1369.

12. Naud J, Laurin LP, Michaud J, Beauchemin S, Leblond FA, et al. (2012) Effects of chronic renal failure on brain drug transporters in rats. Drug Metab Dispos 240: 39-46.

13. Naud J, Michaud J, Boisvert C, Desbiens K, Leblond FA, et al. (2007) Down-regulation of intestinal drug transporters in chronic renal failure in rats. J Pharmacol Exp Ther 320: 978-985.

14. Sun $H$, Frassetto $L$, Benet LZ (2006) Effects of renal failure on drug transport and metabolism. Pharmacol Ther 109:1-11.

15. Kaplan B, Lown K, Craig R, Abecassis M, Kaufman D, et al. (1999) Low bioavailability of cyclosporine microemulsion and tacrolimus in a small bowel transplant recipient: possible relationship to intestinal P-glycoprotein activity. Transplantation 67:333-335.

16. Buchman AL, Paine MF, Wallin A, Ludington SS (2005) A higher dose requirement of tacrolimus in active Crohn's disease may be related to a high intestinal P-glycoprotein content. Dig Dis Sci 50: 2312-2315.

17. Fakhoury M, Lecordier J, Medard Y, Peuchmaur M, Jacqz-Agrain E (2006) Impact of inflammation on the duodenal mRNA expression of CYP3A and P-glycoprotein in children with Crohn's disease. Inflamm Bowel Dis 12:745749.

18. Englund G, Jacobson A, Rorsman F, Artursson P, Kindmark A, et al. (2007) Efflux transporters in ulcerative colitis: decreased expression of BCRP (ABCG2) and Pgp (ABCB1). Inflamm Bowel Dis 13: 291-297.

19. Gutmann H, Hruz P, Zimmermann C, Straumann A, Terracciano L, et al. (2008) Breast cancer resistance protein and P-glycoprotein expression in patients with newly diagnosed and therapy-refractory ulcerative colitis compared with healthy controls. Digestion 78: 154-162.

20. Westerlund M, Belin AC, Olson L, Galter D (2008) Expression of multidrug resistance 1 mRNA in human and rodent tissues: reduced levels in Parkinson patients. Cell Tissue Res 334: 179-185.

21. Ufer M, Häsler R, Jacobs G, Haenisch S, Lächelt S, et al. (2009) Decreased sigmoidal ABCB1 (P-glycoprotein) expression in ulcerative colitis is associated with disease activity. Pharmacogenomics 10: 1941-1953.

22. Blokzijl H, Vander Borght S, Bok LI, Libbrecht L, Geuken M, et al. (2007) Decreased P-glycoprotein (P-gp/MDR1) expression in inflamed human intestinal epithelium is independent of PXR protein levels. Inflamm Bowel Dis 13: 710-720.

23. Provenzani A, Notarbartolo M, Labbozzetta M, Poma P, Vizzini G, et al (2011) Influence of CYP3A5 and ABCB1 gene polymorphisms and other factors on tacrolimus dosing in Caucasian liver and kidney transplant patients. Int J Mol Med 28: 1093-1102.
Int J Clin Pharmacol Pharmacother

ISSN: 2456-3501
IJCPP, an open access journal Volume 2. 2017. 130 
Citation: Murakami T, Ishiguro M, Oda K (2017) Modulation of P-glycoprotein Expression and Function under Disease States in Rats and Humans. Int J Clin Pharmacol Pharmacother 2: 130. doi: https://doi.org/10.15344/2017/2456-3501/130

Page 2 of 3

24. Zhang YJ, Xu JJ, Wang P, Wang JL (2014) Multidrug resistance gene and its relationship to ulcerative colitis and immune status of ulcerative colitis. Genet Mol Res 13: 10837-10851.

25. Andersen V, Vogel U, Godiksen S, Frenzel FB, Sæbø M, et al. (2013) Low $A B C B 1$ gene expression is an early event in colorectal carcinogenesis. PLoS One 8: e72119.

26. Andersen V, Vogel LK, Kopp TI, Sæbø M, Nonboe AW, et al (2015) High ABCC2 and low ABCG2 gene expression are early events in the colorectal adenoma-carcinoma sequence. PLoS One 10: e0119255.

27. Hashida T, Masuda S, Uemoto S, Saito H, Tanaka K, et al. (2001) Pharmacokinetic and prognostic significance of intestinal MDR1 expression in recipients of living-donor liver transplantation. Clin Pharmacol Ther 69: 308-316.

28. Masuda S, Goto M, Kiuchi T, Uemoto S, Kodawara T, et al. (2003) Enhanced expression of enterocyte P-glycoprotein depresses cyclosporine bioavailability in a recipient of living donor liver transplantation. Liver Transpl 9: 1108-1113.

29. Masuda S, Goto M, Okuda M, Ogura Y, Oike F, et al. (2005) Initial dosage adjustment for oral administration of tacrolimus using the intestinal MDR1 level in living-donor liver transplant recipients. Transplant Proc 37: 17281729 .

30. Sharaki O, Zeid M, Moez P, Zakaria NH, Nassar E (2015) Impact of CYP3A4 and MDR1 gene (G2677T) polymorphisms on dose requirement of the cyclosporine in renal transplant Egyptian recipients. Mol Biol Rep 42: $105-117$. 